\title{
KAJIAN KEMAMPUAN KONEKSI MATEMATIK DENGAN PENDEKATAN CONTEXTUAL TEACHING AND LEARNING SISWA SMA PADA MATERI SPLDV
}

\author{
Debby Yuniar ${ }^{1)}$ Lismi Rizki Lisayaroh $^{2}$ Ika Wahyu Anita ${ }^{3}$ Euis Eti Rohaeti ${ }^{4}$ \\ ${ }^{1}$ IKIP Siliwangi Bandung, Jl. Terusan Jenderal Sudirman Cimahi \\ 2 IKIP Siliwangi Bandung, Jl. Terusan Jenderal Sudirman Cimahi \\ ${ }^{3}$ IKIP Siliwangi Bandung, Jl. Terusan Jenderal Sudirman Cimahi \\ ${ }^{4}$ IKIP Siliwangi Bandung, Jl. Terusan Jenderal Sudirman Cimahi \\ Email penulis pertama : debby.yuniar@yahoo.com
}

\begin{abstract}
This study aims to analyze the influence of Contextual Teaching and Learning Approach with the connection capability mathemathic in improving learning in the classroom. This research using qualitative descriptive. There are two cycles to see improvements in student learning activities that have been performed. The population of this research is class X IPS 5 in high school in Bandung regency. Based on student learning activity and student connection ability improved.
\end{abstract}

Keywords: Ability of Mathematical Connection, Contextual Teaching and Learning Approach,

\begin{abstract}
Abstrak
Penelitian ini bertujuan untuk menganalisis pengaruh pendekatan Contextual Teaching and Learning dengan kemampuan Koneksi Matematik dalam meningkatkan pembelajaran di kelas. Penelitian ini menggunnakan deskriptif kualitatif. Terdapat dua siklus untuk melihat peningkatan aktivitas belajar siswa yang telah dilaksanakan. Populasi dalam penelitian ini yaitu kelas X IPS 5 disalah satu SMA di Kabupaten Bandung. Berdasarkan hasil aktivitas belajar siswa dan kemampuan koneksi siswa membaik.
\end{abstract}

Kata Kunci : Kemampuan Koneksi matematik, Pendekatan Contextual Teaching and Learning.

Era globalisasi dan perkembangan teknologi pendidikan merupakan pondasi utama dalam membangun sumber daya manusia yang handal dan berwawasan sehingga dapat meningkatkan mutu dan kualitas pendidikan. Salah satu masalah terbesar yang dihadapi dalam pendidikan ada kaitannya dengan pembelajaran matematika disekolah. Terutama dalam pengembangan kemampuan koneksi matematika.

Maka perlu adanya upaya meningkatkan kemampuan koneksi tersebut untuk mendukung tujuan pembelajaran. Menurut penelitian yang dilakukan Ruspiani (2000) (dalam Mandur, Sandra, \& Suparta: 2013) mengungkapkan bahwa kemampuan siswa dalam melakukan koneksi matematis memang masih tergolong rendah, hasil penelitiannya menunjukan nilai rata-rata kemampuan koneksi matematis siswa sekolah menengah masih rendah yaitu kurang dari 60 pada skor 100 (22,2\% untuk koneksi matematika pada pokok bahasan lain, 44\% untuk koneksi pada bidang studi lain, dan 67,3\% untuk koneksi matematika pada kehidupan sehari-hari). Dari hasil penelitian ini menunjukan bahwa siswa tidak hanya dituntut untuk memahami materi, tetapi juga harus bisa menjelaskan keterkaitan antar konsep matematika dengan bidang ilmu lain diantarannya, fisika, biologi dan kimia dan mengaplikasikannya dalam kehidupan sehari-hari. 
Kemampuan koneksi matematika adalah kemampuan siswa dalam mengaitkan dan menghubungkan berbagai materi matematika dengan matematika, dan matematika dengan bidang ilmu yang lain untuk meningkatkan kemampuan belajar siswa.

NCTM (Anita, 2014:128) menyebutkan tujuan siswa memiliki kemampuan koneksi matematis agar siswa mampu untuk :

1. Mengenali dan menggunakan koneksi antara gagasan- gagasan matematika;

2. Memahami bagaimana gagasan-gagasan matematik saling berhubungan dan berdasar pada satu sama lain untuk menghasilkan suatu keseluruhan koheren (padu);

3. Mengenali dan menerapkan matematika baik didalam maupun diluar konteks matematika.

Hal di atas menunjukan pentingnya kemampuan koneksi matematis, tetapi menurut beberapa penelitian masih tergolong rendah. Tanpa kemampuan koneksi yang baik, perkembangan matematika akan terhambat. Maka perlu adanya upaya meningkatkan kemampuan koneksi untuk mencapai tujuan tersebut salah satu solusinya ialah dengan menerapkan pembelajaran inovatif yaitu dengan menggunakan pendekatan kontekstual. Pendekatan kontekstual merupakan pendekatan pembelajaran yang mengaitkan materi yang diajarkan dengan konteks kehidupan sehari - hari mereka sehingga pembelajaran menjadi lebih bermakna bagi siswa.

NTCM (dalam Hendriana, Rohaeti, Sumarmo 2017 : 85) merangkum indikator koneksi matematis dalam tiga komponen besar yaitu : a) mengenali dan menggunakan hubungan antar ide-ide dalam matematika; b) memahami keterkaitan ide-ide matematika dan membentuk ide matematika baru yang lain sehingga menghasilkan suatu keterkaitan yang menyeluruh; c) mengenali dan mengaplikasikan satu konten matematika ke dalam konten matematika lain dan ke lingkungan di luar matematika.

Sanjaya (2008 : 255) memberikan pengertian pendekatan kontekstual adalah suatu strategi pembelajaran yang menekankan materi yang dipelajari untuk dihubungkan dengan situasi kehidupan yang nyata, sehingga mendorong siswa untuk dapat menerapkan dalam kehidupan mereka. Suyanto (dalam Setyawan 2011: 44) mengartikan pembelajaran kontekstual sebagai suatu paham belajar mengajar yang memandang pentingnya hubungan antara materi pembelajaran dengan dunia nyata, serta melihat pentingnya dorongan dan keterlibatan siswa untuk mampu menghubungkan konsep yang dipelajari dengan aplikasinya dalam kehidupan sehari- hari.

Dari beberapa pendapat tersebut dapat disimpulkan bahwa pendekatan kontekstual adalah kemampuan untuk mendorong siswa dalam mengaitkan materi pembelajaran dengan kehidupan nyata. Secara gari besar langkah- langkah kemampuan kontekstual (Depdiknas, 2002: 5) dalam kelas sebagai berikut: (1) Kembangkan pemikiran bahwa anak-anak akan belajar lebih bermakna dengan cara bekerja sendiri, menemukan sendiri, dan mengkontruksi sendiri pengetahuan dan keterampilan barunya, (2) laksanakan sejauh mungkin kegiatan inkuiri untuk semua topik, (3) kembangkan sifat ingin tahu dengan bertanya, (4) Ciptakan masyarakat belajar (belajar dalam kelompok-kelompok), (5) 
hadirkan model sebagai contoh pembelajaran, (6) lakukan refleksi diakhir pertemuan, (7) lakukan penilaian yang sebenarnya dengan berbagai cara.

\section{METODE}

Metode penelitian yang diambil adalah Penelitian Tindakan Kelas (PTK) yaitu penelitian yang diharapkan memberikan informasi bagaimana tindakan unruk meningkatkan kemampuan guru dan penguasaan konsep siswa dalam pembelajaran matematika. Kemmis dan Mc. Taggart (Arikunto, 2006 : 93) menjelaskan ada 4 komponen yang di dalam metode penelitian PTK, yaitu; perencanaan (planning), pelaksanaan (action), pengamatan (observation), dan refleksi (reflection).

Penelitian tindakan kelas ini bertujuan untuk mengungkapkan (1) Bagaimana pendekatan Contextual Teaching and Learning dapat meningkatkan aktivitas belajar siswa (2) Bagaimana pendekatan Contextual Teaching and Learning dapat meningkatkan koneksi matematis siswa di kelas X IPS di salah satu SMA di Kabupaten Bandung.

Adapun langkah-langkah kegiatan pembelajaran dengan menggunakan pendekatan Contextual Teaching and Learning sebagai berikut dilakukan kegiatan kontruktivisme untuk mengingatkan dan membangun siswa akan pembelajaran yang telah didapat di SMP, dibuat komunitas belajar agar siswa lebih aktif dan diarahkan untuk berfikir bersama-sama kelompok, sehingga tercipta inkuiri setelah guru memberikan contoh pembelajaran, lakukan refleksi dan penilaian di akhir pertemuan.

Kegiatan awal :

1. Guru mengecek kehadiran siswa dan meminta siswa mempersiapkan perlengkapan belajar;

2. Guru memberikan ice breaking terlebih dahulu agar siswa dapat lebih bersemangat dalam mengikuti pembelajaran;

3. Guru mengingatkan pembelajaran SPLDV yang sebelumnya telah dipelajari;

4. Guru menyampaikan tujuan pembelajaran yang akan dicapai.

Kegiatan Inti :

1. Guru mengingatkan kembali materi SPLDV untuk memancing pengetahuan yang telah didapat siswa;

2. Siswa dibagi beberapa kelompok yang setiap kelompoknya heterogen agar siswa yang aktif bergabung dengan siswa yang masih terlihat pasif;

3. Siswa diberikan LKS untuk di selesaikan dan dipecahkan bersama kelompoknya;

4. Guru memberikan contoh bentuk SPLTV dan beberapa penyelesaian menggunakan media gambar untuk membuat kalimat matematika yang tepat; Siswa berdiskusi dan mencoba menyelesaikan permasalahan yang terdapat di LKS;

5. Guru berkeliling dan membimbing siswa yang mengalami kesulitan menyelesaikan permasalahan SPLTV;

6. Guru meminta setiap siswa memaparkan hasil diskusi di depan kelas.

Kegiataan Penutup: 
1. Guru memberikan penilaian;

2. Guru dan siswa bersama- sama menyimpulkan kegiatan dan hasil pembelajaran.

3.

\section{HASIL DAN PEMBAHASAN}

Penelitian tindakan kelas ini terdiri dari dua siklus pembelajaran menggunakan pendekatan Contextual Teaching and Learning dengan tujuh langkah- langkah ; kontruktivisme, inkuiri, bertanya, komunitas belajar, pemodelan, refleksi dan penilaian. Pada siklus I kegiatan penelitian dilaksanakan sesuai dengan skenario yang telah dibuat. Selama pelaksanaan tindakan kelas dilakukan pengamatan terhadap aktivitas belajar siswa yang sesuai dengan Contextual Teaching and Learning.

Tabel 1. Hasil pengamatan aktivitas siswa pada siklus I

\begin{tabular}{|c|c|c|c|c|}
\hline \multirow{2}{*}{ Aktivitas } & \multicolumn{2}{|c|}{ Pertemuan $\%$} & \multirow{2}{*}{ Rata-rata \% } & \multirow{2}{*}{ Kategori } \\
\cline { 2 - 3 } & 1 & 2 & & Kurang Sekali \\
\hline A & 10 & 16.6 & 13.30 & Baik \\
\hline B & 69.4 & 83.3 & 76.35 & Cukup \\
\hline C & 60 & 55.5 & 57.75 & Cukup \\
\hline D & 45 & 55.5 & 50.25 & Kurang \\
\hline E & 25 & 41.6 & 33.30 & Baik Sekali \\
\hline F & 80 & 88.8 & 84.40 & Cukup \\
\hline G & 35 & 52.7 & 43.85 & Kurang Sekali \\
\hline H & 15 & 19.4 & 17.20 & Cukup \\
\hline Siswa yang hadir & 35 & 36 & 47.05 & \\
\hline
\end{tabular}

\section{Keterangan :}

A: Merespon/ menjawab pertanyaan dari guru / memberikan tanggapan.

B: Mencatat hal-hal yang penting/ intisari dari materi pembelajaran.

C: Mengajukan pertanyaan kepada guru.

D: Menyelidiki, membaca, mencermati dan menemukan solusi LKS.

E: Bertanya/ memberi penjelasan kepada teman dalam kelompok belajar.

F: Mencatat hasil diskusi kelompok / membuat kesimpulan.

G: Mempresentasikan hasil diskusi kelompok.

H: Melakukan kegiatan yang tidak relevan pada proses pembelajaran, seperti mengobrol dan lain-lain.

Dari tabel diatas menunjukan bahwa hasil pertemuan kedua aktivitas siswa mengalami peningkatan. Namun adapula indikator yang belum meningkat terlihat dari indikator siswa dalam respon/ menjawab pertanyaan dari guru / memberikan tanggapan dan dalam melakukan kegiatan yang tidak relevan pada proses pembelajaran, seperti mengobrol dan lain-lain termasuk dalam kategori kurang sekali. Selain itu untuk indikator dalam menyelidiki, membaca, mencermati dan menemukan solusi LKS termasuk dalam kategori kurang.

Untuk melihat kemampuan Koneksi matematik siswa pada siklus I peneliti melakukan kuis pertama yang terdidri dari dari 5 butir essay. Hasil tes kemampuan koneksi matematik siswa untuk siklus I tertera pada 
Tabel 2. Pencapaian KKM Pada Tes Siklus I

\begin{tabular}{|c|c|c|}
\hline No & Nilai & Ketuntasan \\
\hline 1 & 60 & Tidak Tuntas \\
\hline 2 & 80 & Tuntas \\
\hline 3 & 72 & Tuntas \\
\hline 4 & 30 & Tidak Tuntas \\
\hline 5 & 20 & Tidak Tuntas \\
\hline 6 & 60 & Tidak Tuntas \\
\hline 7 & 45 & Tidak Tuntas \\
\hline 8 & 37 & Tidak Tuntas \\
\hline 9 & 70 & Tuntas \\
\hline 10 & 60 & Tidak Tuntas \\
\hline 11 & 30 & Tidak Tuntas \\
\hline 12 & 28 & Tidak Tuntas \\
\hline 13 & 15 & Tidak Tuntas \\
\hline 14 & 15 & Tidak Tuntas \\
\hline 15 & 60 & Tidak Tuntas \\
\hline 16 & 28 & Tidak Tuntas \\
\hline 17 & 30 & Tidak Tuntas \\
\hline 18 & 20 & Tidak Tuntas \\
\hline 19 & 45 & Tidak Tuntas \\
\hline 20 & 20 & Tidak Tuntas \\
\hline 21 & 60 & Tidak Tuntas \\
\hline 22 & 25 & Tidak Tuntas \\
\hline 23 & 28 & Tidak Tuntas \\
\hline 24 & 20 & Tidak Tuntas \\
\hline 25 & 21 & Tidak Tuntas \\
\hline 26 & 25 & Tidak Tuntas \\
\hline 27 & 22 & Tidak Tuntas \\
\hline 28 & 20 & Tidak Tuntas \\
\hline 29 & 20 & Tidak Tuntas \\
\hline 30 & 15 & Tidak Tuntas \\
\hline 31 & 24 & Tidak Tuntas \\
\hline 32 & 49 & Tidak Tuntas \\
\hline 33 & 25 & Tidak Tuntas \\
\hline 34 & 21 & Tidak Tuntas \\
\hline 35 & 25 & Tidak Tuntas \\
\hline 36 & 25 & Tidak Tuntas \\
\hline \multicolumn{2}{|c|}{ Rata-Rata } & $34.7 \%$ \\
\hline
\end{tabular}

Pada Tabel 2 terlihat bahwa jumlah siswa yang tuntas untuk koneksi matematik siswa adalah 3 siswa (8,3\% dari 36 siswa) dengan rata-rata kelas $34,7 \%$. Hasil tes menunjukan bahwa siswa masih belum memuaskan dalam kemampuan koneksi matematik. Siswa masih banyak yang mengalami kesulitan ketika menghubungkan antar topik matematika dengan matematika. Setelah siklus I dilaksanakan, peneliti melakukan wawancara dengan guru dan siswa dari hasil wawancara terungkap 
bahwa keaadaan siswa dalam belajar menggunakan pendekatan kontekstual, lebih cepat mengerti dan dapat bertukar pikiran bersama anggota kelompok.

Berdasarkan hasil pengamatan peneliti dan observer bahwa masih banyak indikator keberhasilan aktivitas belajar siswa yang belum tercapai, dan kemampan matematika masih harus ditingkatkan lagi. Maka dari itu perlu dilakukan tindakan kelas dan pembelajaran pada siklus II.

Tabel 3. Hasil pengamatan aktivitas siswa pada siklus II

\begin{tabular}{|c|c|c|c|c|}
\hline \multirow{2}{*}{ Aktivitas } & \multicolumn{2}{|c|}{ Pertemuan \% } & \multirow{2}{*}{ Rata-rata \% } & \multirow{2}{*}{ Kategori } \\
\cline { 2 - 3 } & 1 & 2 & & Kurang \\
\hline A & 27.7 & 41.6 & 34.65 & Baik Sekali \\
\hline B & 88.8 & 94.4 & 91.6 & Baik \\
\hline C & 63.8 & 69.4 & 66.6 & Baik \\
\hline D & 55.5 & 75.0 & 65.25 & Cukup \\
\hline E & 50.0 & 66.6 & 58.3 & Baik Sekali \\
\hline F & 91.6 & 97.2 & 94.4 & Baik Sekali \\
\hline G & 80.5 & 83.3 & 81.9 & Kurang \\
\hline H & 33.3 & 41.6 & 37.45 & Baik \\
\hline Siswa yang hadir & 36 & 36 & 66.26 & \\
\hline
\end{tabular}

Pada tabel 3 terlihat bahwa pada pertemuan ke 4 semua aktivitas siswa mengalami peningkatan dari pertemuan sebelumnya. Siswa terlihat antusias dalam mengerjakan LKS dan terlibat aktif dalam menyelesaikan persoaalan dalam LKS. Siswa sudah aktif berdiskusi bersama kelompok. Siswa mampu mempresentasikan hasil diskusi kelompoknya dengan lebih percaya diri.

Rata-rata aktivitas pada siklus I dengan aktivitas siklus II, dapat dilihat bahwa aktivitas siswa merespon/ menjawab pertanyaan guru/ memberikan tanggapan meningkat $21.35 \%$, aktivitas siswa mencatatat hal-hal yang penting/ intisari dari materi pembelajaran meningkat $15.25 \%$, aktivitas siswa mengajukan pertanyaan kepada guru meningkat 8,85\%, aktivitas siswa menyelidiki/ membaca/ mencermati/ menemukan solusi LKS meninhkat 15\%, aktivitas siswa bertanya/ memberi pejelasan kepada teman dalam kelompok belajar meningkat 25\%, aktivitas siswa mencatata hasil diskusi kelompok/ membuat kesimpulan meningkat menjadi kategori baik sekali 10\%, aktivitas siswa mempresentasikan hasil diskusi kelompok meningkat 38.05\%, dan aktivitas siswa melakukan kegiatan yang tidak relevan pada proses pembelajaran seperti mengobrol dan lain-lain meningkat $20.25 \%$.

Tabel 4. Pencapaian KKM Pada Tes Siklus II

\begin{tabular}{|c|c|c|}
\hline No & Nilai & Ketuntasan \\
\hline 1 & 95 & Tuntas \\
\hline 2 & 90 & Tuntas \\
\hline 3 & 80 & Tuntas \\
\hline 4 & 85 & Tuntas \\
\hline 5 & 85 & Tuntas \\
\hline 6 & 80 & Tuntas \\
\hline
\end{tabular}




\begin{tabular}{|c|c|c|}
\hline 7 & 80 & Tuntas \\
\hline 8 & 87 & Tuntas \\
\hline 9 & 70 & Tuntas \\
\hline 10 & 55 & Tidak Tuntas \\
\hline 11 & 70 & Tuntas \\
\hline 12 & 79 & Tuntas \\
\hline 13 & 78 & Tuntas \\
\hline 14 & 75 & Tuntas \\
\hline 15 & 75 & Tuntas \\
\hline 16 & 76 & Tuntas \\
\hline 17 & 73 & Tuntas \\
\hline 18 & 70 & Tuntas \\
\hline 19 & 70 & Tuntas \\
\hline 20 & 70 & Tuntas \\
\hline 21 & 75 & Tuntas \\
\hline 22 & 55 & Tidak Tuntas \\
\hline 23 & 55 & Tidak Tuntas \\
\hline 24 & 78 & Tuntas \\
\hline 25 & 70 & Tuntas \\
\hline 26 & 60 & Tidak Tuntas \\
\hline 27 & 60 & Tidak Tuntas \\
\hline 28 & 65 & Tidak Tuntas \\
\hline 29 & 62 & Tidak Tuntas \\
\hline 30 & 59 & Tidak Tuntas \\
\hline 31 & 58 & Tidak Tuntas \\
\hline 32 & 70 & Tuntas \\
\hline 33 & 55 & Tidak Tuntas \\
\hline 34 & 55 & Tidak Tuntas \\
\hline 35 & 75 & Tuntas \\
\hline 36 & 78 & Tuntas \\
\hline \multicolumn{2}{|c|}{ Rata-Rata } & $71 \%$ \\
\hline
\end{tabular}

Pada Tabel 4 terlihat bahwa jumlah siswa yang tuntas untuk koneksi matematik siswa adalah 25 siswa (69.4\% dari 36 siswa) dengan rata-rata kelas $71 \%$. Hal ini menunjukan kemampuan koneksi matematik siswa sudah meningkat secara klasikal .

Berdasarkan wawancara yang dilakukan peneliti, siswa merasa tertarik mempelajari matematika karena dirasakan langsung penerapannya dalam kehidupan sehari-hari. Siswa juga mengatakan bahwa mempelajari SPLTV seperti ini, membiasakan mereka untuk memahami dan mencermati persoaalan dalam melakukan hubungan antar topik. Berdasarkan hasil refleksi, peneliti bersama observer sepakat untuk menghentikan tidakan sampai pada siklus II. Hal ini dikarenakan seluruh indicator keberhasilan aktivitas belajar siswa sudah terpenuhi dan kemampuan koneksi matematik sudah cenderung membaik. 


\section{KESIMPULAN}

Kesimpulan yang didapat dari hasil penelitian tindakan kelas ini, bahwa pembelajaran matematika dengan menggunakan pendekatan Contextual Teaching and Learning (CTL) dapat membantu meningkatkan aktivitas belajar siswa. Dan dengan menggunakan pendekatan Contextual Teaching and Learning (CTL) dapat memperbaiki kemampuan koneksi matematik siswa kelas X IPS 5 di salah satu SMA di Kabupaten Bandung pada materi Sistem Persamaan Linear Tiga Variabel. Hal tersebut menunjukan bahwa terdapat suatu korelasi yang positif antara pendekatan Contextual Teaching and Learning dengan kemampuan koneksi matematik siswa.

\section{DAFTAR PUSTAKA}

Anita, I. W. (2014). Pengaruh Kecemasan Matematika (Mathematics anxiety) terhadap Kemampuan Koneksi Matematis siswa SMP. Infinity Journal, 3(1), 125-132.

Astuti, A. (2016). Penerapan Metode Penemuan Terbimbing Untuk Meningkatkan Aktivitas Dan Hasil Belajar Matematikasiswa Kelas Xii Ips Sma Negeri 1 Salo. Jurnal Cendekia : Jurnal Pendidikan Matematika, (1), 1-14. Retrieved

From Http://Journal.Stkiptam.Ac.Id/Index.Php/Cendekia/Article/View/646

Arikunto, S (2006). Prosedur Penelitian. Jakarta: PT. Rineka Cipta.

Depdiknas. (2002). Pendekatan Kontekstual (Contextual Teaching and Learning). Jakarta: Direktorat Pendidikan Lanjutan Pertama, Direktorat Jendral Pendidikan Dasar Menengah.

Hendriana, H, Rohaeti, E.E \& Sumarmo, U. (2017). Hard Skills dan Soft Skills Matematik Siswa. Bandung: Reflika Aditama.

Mandur, K. Sandra, I.W., \& Suparta, I.N. (2013). Kontribusi Kemampuan Koneksi, Kemampuan Representasi, dan Disposisi Matematis Terhadap Prestasi Belajar Matematika Siswa SMA Swasta di Kabupaten Bandung. e-Journal Program Pasca Sarjana Universitas Pendidikan Ganesha (vol. 2).

Sanjaya, W. (2008). Strategi Pembelajaran. Jakarta: Prenada Media Group.

Zulfah, Z. (2018). Pengaruh Penerapan Model Pembelajaran Kooperatif Tipe Think Pair Share Dengan Pendekatan Heuristik Terhadap Kemampuan Pemecahan Masalah Matematis Siswa Mts Negeri Naumbai Kecamatan Kampar.Jurnal Cendekia : Jurnal Pendidikan Matematika, (2), 65-76. Retrieved From Http://Journal.Stkiptam.Ac.Id/Index.Php/Cendekia/Article/View/634 